\title{
Hubungan Bentuk, Rasa Makanan, dan Cara Penyajian dengan Sisa Makanan Selingan Pada Pasien Anak di Rumah Sakit Angkatan Laut Dr. Ramelan Surabaya
}

\section{Correlation between the Form, Taste, Serving Method of Snacks and Plate Waste among Pediatric Patients at Dr. Ramelan Naval Hospital Surabaya}

\author{
Rizka Fikriana Kartini*, Suzanna Primadona ${ }^{1}$
}

\begin{abstract}
ABSTRAK
Latar Belakang: Sisa makanan dalam kategori banyak (>20\%) masih ditemukan dalam beberapa rumah sakit di Indonesia. Hal tersebut dapat berdampak pada lamanya masa perawatan di rumah sakit dan peningkatan biaya perawatan yang dikeluarkan oleh pasien. Faktor penampilan dan rasa makanan dapat mempengaruhi terjadinya sisa makanan.

Tujuan: Untuk menganalisis hubungan antara bentuk, metode penyajian, pengecapan, dan sisa makanan camilan di antara pasien pediatrik di Rumah Sakit Angkatan Laut Dr. Ramelan Surabaya.

Metode: Peneltian ini menggunakan desain studi observasional dengan rancangan penelitian cross sectional. Besar sampel penelitian adalah 34 responden. Pasien anak usia 2-12 tahu yang sedang dirawat di ruang rawat inap kelas II dan III menjadi sampel penelitian ini. Wawancara dan observasi menggunakan kuesioner yang meliputi karakteristik responden, sisa makanan selingan dengan metode Comstock digunakan untuk mengumpulkan data primer. Uji statistik menggunakan uji Chi square untuk mengetahui apakah ada hubungan antara bentuk makanan, cara penyajian, dan rasa makanan dengan sisa makanan selingan.

Hasil: Rata-rata sisa makanan selingan pada responden yang menyatakan bentuk makanan sangat sesuai sebesar $26,38 \%$, cara penyajian sangat sesuai sebesar $32,95 \%$, dan rasa makanan sangat sesuai sebesar $6,25 \%$. Bentuk makanan $(p=0,046)$, cara penyajian $(p=0,026)$, dan rasa makanan $(p=0,003)$ memiliki hubungan yang signifikan dengan sisa makanan selingan.

Kesimpulan: Bentuk makanan, cara penyajian, dan rasa makanan berhubungan dengan sisa makanan selingan pada pasien anak.
\end{abstract}

Kata kunci: bentuk makanan, cara penyajian, rasa makanan, sisa makanan

\section{ABSTRACT}

Background: Several hospital in Indonesia are found to have more than $20 \%$ food leftover. It influences patient's treatment duration as well as increases the costs. Food leftover or plate waste might be caused by food presentations and taste.

Objectives: To analyze the relationship between the form, serving method, taste, and the plate waste of snacks among pediatric patients in Dr. Ramelan Naval Hospital Surabaya.

Method: This was a cross sectional research. The samples were 34 respondents aged 2-12 years old, having inpatient treatments in class II and III. The primary data collection were taken by interview and observation using questionnaires about plate waste of snacks in which Comstock method. The 
statistical test used was chi square test to determine the relationship between the form, serving method, taste, and the plate waste of snacks.

Result: The average of respondents plate waste based on the form were $26.38 \%$, serving method were $32.95 \%$, and taste as very appropriate were $6.25 \%$. The form ( $p=0.046)$, serving method $(p=0.026)$ and taste ( $p=0.003$ ) was significantly related to the plate waste of snacks.

Conclusion: The form, serving method and taste of snacks were correlated to the plate waste among pediatric patients at The Dr. Ramelan Naval Hospital Surabaya.

Keywords: snacks, form, serving method, taste, plate waste

\author{
*Koresponden: \\ rizkafika97@gmail.com \\ ${ }^{1}$ Sub Departemen Gizi-Rumah Sakit Angkatan Laut Dr. Ramelan, Surabaya
}

\section{PENDAHULUAN}

Perencanaan menu, kebutuhan bahan makanan, anggaran belanja, pengadaan bahan makanan, penerimaan dan penyimpanan, pemasakan bahan makanan, distribusi dan pencatatan, pelaporan, serta evaluasi merupakan suatu rangkaian kegiatan dalam penyelengaraan makanan di rumah sakit. Makanan yang berkualitas sesuai kebutuhan gizi, aman, biaya, dan dapat diterima oleh pasien merupakan suatu tujuan dari penyelenggaraan makanan di rumah sakit. Dengan demikian, pemberian makanan yang berkualitas dapat mendukung tercapainya status gizi pasien yang optimal ${ }^{1}$.

$$
\text { Jumlah sisa makanan dan }
$$

perkembangan keadaan gizi pasien rawat inap menjadi indicator keberhasilan pelayanan gizi di rumah sakit ${ }^{2}$. Sisa makanan yang tidak termakann oleh pasien dapat menggambarkan efektivitas dan efisiensi pelayanan instalasi gizi. indicator sisa makanan rumah sakit yang tidak termakan oleh pasien adalah $\leq 20 \%$ sesuai dengan Kepmenkes No. 129/ Menkes/ SK/ II/2008 mengenai Standar Pelayanan Minimal Rumah Sakit ${ }^{3}$. Dalam penelitian Habiba di Rumah Sakit Jemursari Surabaya tahun 2017 menunjukkan bahwa rata-rata sisa makanan pagi sebesar $25.1 \%$. makanan jenis sayur memiliki sisa makanan terbanyak (34.3\%). Sisa makanan paling sedikit terdapat pada jenis lauk nabati $(16.6 \%)^{4}$. Penelitian di Rumah Sakit Holistik Purwakarta oleh Fatkhurohman tahun 2017 menunjukkan bahwa rata-rata sisa makanan pasien sebesar $46.2 \%^{5}$. Asupan gizi pasien yang tidak adekuat dapat dilihat melalui adanya sisa makanan. lamanya masa perawatan pasien di rumah sakit dan peningkatan biaya yang dikeluarkan menjadi dampak dari pasien yang mengalami malnutrisi 6 .

Kelompok usia anak merupakan kelompok usia yang sering ditemui mengalami fase perilaku kesulitan makan ${ }^{7}$. Diketahui bahwa anak cenderung menyukai makanan selingan dibanding makanan utama. Hal tersebut didukung pada survei yang dilakukan di Unit Pediatri Rawat Jalan Rumat Sakit Dr. Cipto Mangunkusumo Jakarta oleh Soedibyo dan Mulyani tahun 2008 menunjukkan bahwa sebagian besar anak yang mengalami kesulitan makan hanya mampu menghabiskan makanan kurang dari sepertiga porsi ${ }^{8}$. Sisa makanan rumah sakit dipengaruji oleh beberapa faktor, yaitu berkaitan dengan kondisi klinis pasien, rasa dan penampilan makanan (kualitas makanan, besar porsi, dan jenis menu), pelayanan makanan, waktu penyajian makanan, dan kondisi ruang perawatan ${ }^{9,10}$. Dalam penelitian yang dilakukan di RSUD Sunan Kalijaga Kabupaten Demak tahun 2013 disebutkan bahwa semakin tinggi tingkat kepuasan pelayanan makanan maka terjadinya penurunan status gizi pasien juga semakin kecill ${ }^{11}$. Namun berdasarkan penelitian sebelumnya di RSUD Gunung Jati Cirebon oleh Ariefuddin diketahui bahwa sisa makanan selingan tidak berhubungan dengan kepuasan responden mengenai mutu makanan tersebut ${ }^{2}$. Seluruh responden memiliki sisa makanan selingan dalam kategori sedikit $(\leq 25 \%)$ dan menyatakan puas terhadap mutu makanan². 
Penelitian mengenai sisa makanan pasiean anak masih jarang ditemui dan belum pernah dilakukan di Ruang Rawat Inap RUMKITAL Dr. Ramelan Surabaya. Penelitian ini bertujuan untuk menganalisis hubungan antara bentuk makanan, rasa makanan, dan cara penyajian dengan sisa makanan selingan pada pasien anak di Ruang Rawat Inap RUMKITAL Dr. Ramelan Surabaya. Hasil penelitian diharapkan dapat menjadi evaluasi penyelenggaraan makanan rumah sakit, terutama pada pasien anak.

\section{METODE}

Desain studi yang digunakan dalam penelitian ini adalah observasional, dengan rancangan penelitian cross sectional. Penelitian dilaksanakan di RUMKITAL Dr. Ramelan Surabaya. Jenis penelitian ini digunakan untuk mengetahui hubungan bentuk makanan, rasa makanan, dan cara penyajian dengan sisa makanan selingan rumah sakit pada pasien anak. Seluruh pasien anak di Ruang Rawat Inap RUMKITAL Dr. Ramelan Surabaya merupakan populasi dalam penelitian ini. Besar sampel penelitian sebanyak 34 responden. Kriteria pasien yang menjadi sampel penelitian ini adalah pasien anak usia 2-12 tahun yang telah rawat inap minimal selama 24 jam dan dirawat di ruang rawat inap kelas II dan III.

Metode wawancara dan observasi menggunakan kuesioner yang meliputi karakteristik responden, sisa makanan selingan dengan metode Comstock ${ }^{12,13}$, dan penilaian terhadap bentuk makanan, cara penyajian, dan rasa makanan selingan sebagai data primer. Kuesioner penilaian makanan menggunakan skala Likert dengan tiga kategori penilaian yaitu kurang sesuai, cukup sesuai, dan sangat sesuai yang masing-masing diberi skor 1-3, kemudian dikompositkan dan dikatakan kurang sesuai apabila skor $<60 \%$, cukup sesuai apabila skor $60-80 \%$, dan sangat sesuai apabila skor $>80 \%{ }^{14,15}$. Metode Comstock telah dilakukan uji validitas yang membandingkan dengan penimbangan sisa makanan dan memberikan hasil yang cukup baik ${ }^{9}$. Wawancara dilakukan kepada wali/orang tua responden. Data sekunder diperoleh dari Subdeb Gizi RUMKITAL Dr. Ramelan Surabaya mengenai jumlah pasien anak dalam kurun waktu satu tahun terakhir. Data dianalisis melalui uji Chi square dengan tujuan untuk mengetahui apakah terdapat hubungan anatara bentuk makanan,

rasa makanan, dan cara penyajian dengan sisa makanan selingan rumah sakit pada pasien anak dengan nilai $\alpha=0,05$.

\section{HASIL DAN PEMBAHASAN}

Jika dilihat pada tabel 1 , menunjukkan bahwa mayoritas responden berjenis kelamin laki-laki $(70,6 \%)$.

Responden yang belum bersekolah sebanyak 44,1\%. Mayoritas pendidikan terakhir orang tua responden adalah tamat SMA/sederajat $(58,8 \%)$ dengan status pekerjaan sebagian besar merupakan anggota Tentara Nasional Indonesia Angkatan Laut (41,2\%). Terdapat 10 jenis diet yang diberikan rumah sakit kepada responden. Sebanyak 7 responden $(20,6 \%)$ mendapatkan nasi biasa pantang, 7 responden $(20,6 \%)$ mendapatkan nasi tim pantang, 7 responden (20,6\%) mendapatkan nasi tim lauk cacah pantang, dan sisanya mendapatkan jenis diet lain.

Makanan selingan merupakan makanan yang disajikan dalam jumlah kecil diantara makanan lainnya. Bagi pasien yang dinilai rentan terhadap malnutrisi, penyediaan makanan selingan merupakan salah satu cara untuk mengatasi masalah nafsu makan yang buruk dan risiko kekurangan gizi. makanan selingan dapat meningkatkan nafsu makan pasien, sehingga dapat dengan mudah memperbaiki asupan gizi pasien ${ }^{16}$. Dalam penyelenggaraan makanan di RUMKITAL Dr. Ramelan Surabaya khususnya makanan selingan, diketahui bahwa terdapat 16 responden yang menghabiskan makanan selingan $(47,1 \%), 1$ responden menyisakan sedikit $(2,9 \%), 5$ responden menyisakan setengah porsi $(14,7 \%), 6$ responden menyisakan banyak (17,6\%), dan 6 responden tidak memakan makanan selingan $(17,6 \%)$. Hal tersebut sesuai dengan penelitian sebelumnya bahwa makanan selingan dapat meningkatkan nafsu makan pasien ${ }^{16}$.

Dalam penelitian ini, terdapat Sembilan aspek penilian makanan yaitu bentuk, cara penyajian, rasa, warna, konsistesi, besar porsi, aroma, tingkat kematangan, dan suhu 
Tabel 1. Distribusi Frekuensi Karakteristik

\begin{tabular}{lcc}
\multicolumn{3}{c}{ Responden } \\
\hline $\begin{array}{l}\text { Karakteristik } \\
\text { Responden }\end{array}$ & $\begin{array}{c}\text { Frekuensi } \\
(\mathbf{n})\end{array}$ & $\begin{array}{c}\text { Persentase } \\
(\%)\end{array}$ \\
\hline $\begin{array}{l}\text { Jenis Kelamin } \\
\quad \text { Laki-laki }\end{array}$ & 24 & 70,6 \\
$\quad \begin{array}{l}\text { Perempuan } \\
\text { Pendidikan }\end{array}$ & 10 & 29,4 \\
Responden & & \\
$\quad$ Belum sekolah & 15 & 44,1 \\
$\quad$ SD/MI & 10 & 29,4 \\
$\quad$ TK & 9 & 26,5 \\
Pendidikan Terakhir Orang Tua & \\
$\quad$ SD/SMP & 4 & 11,8 \\
$\quad$ SMA & 20 & 58,8 \\
Diploma/Sarjana & 10 & 29,4
\end{tabular}

\section{Pekerjaan Orang}

Tua

Ibu rumah

Tangga

Pegawai Swasta

PNS

TNI AL

Wiraswasta

Jenis Diet

Bubur sum-sum

Bubur sum-sum

pantang

Nasi biasa

Nasi biasa

pantang

Nasi rendah

garam

Nasi tim

Nasi tim pantang

Nasi tim lauk

cacah

Nasi tim lauk

cacah pantang

Nasi tim saring

pantang

penyajian. Namun terdapat enam aspek yang menunjukkan tidak terdapat hubungan dengan kejadian sisa makanan selingan pada pasien anak, yaitu warna, konsistensi, besar porsi, aroma, tingkat kematangan, dan suhu penyajian. Tabel 2 menunjukkan bahwa sebanyak 6 responden $(17,6 \%)$ menyatakan warna makanan kurang sesuai, sebanyak 1 responden $(2,9 \%)$ menyatakan besar porsi dan rasa makanan kurang sesuai. Sebagian besar
Tabel 2. Hubungan Faktor Eksternal dengan Sisa Makanan Selingan Pasien Anak

\begin{tabular}{|c|c|c|c|}
\hline Variabel & $\begin{array}{l}\text { Frekuensi } \\
\text { (n) }\end{array}$ & $\begin{array}{c}\text { Persentase } \\
\text { (\%) }\end{array}$ & $\begin{array}{c}P \\
\text { value }\end{array}$ \\
\hline \multicolumn{4}{|l|}{ Warna } \\
\hline $\begin{array}{l}\text { Kurang } \\
\text { Sesuai }\end{array}$ & 6 & 17,6 & \multirow{3}{*}{0,765} \\
\hline Sesuai & 10 & 29,4 & \\
\hline $\begin{array}{l}\text { Sangat } \\
\text { Sesuai }\end{array}$ & 18 & 52,9 & \\
\hline \multicolumn{4}{|l|}{ Bentuk } \\
\hline Sesuai & 16 & 47,1 & \multirow{2}{*}{$0,046^{*}$} \\
\hline $\begin{array}{l}\text { Sangat } \\
\text { Sesuai }\end{array}$ & 18 & 52,9 & \\
\hline \multicolumn{4}{|l|}{ Konsistensi } \\
\hline Sesuai & 13 & 38,2 & \multirow{2}{*}{0,445} \\
\hline $\begin{array}{l}\text { Sangat } \\
\text { Sesuai }\end{array}$ & 21 & 61,8 & \\
\hline \multicolumn{4}{|l|}{ Besar Posi } \\
\hline $\begin{array}{l}\text { Kurang } \\
\text { Sesuai }\end{array}$ & 1 & 2,9 & \multirow{3}{*}{0,632} \\
\hline Sesuai & 16 & 47,1 & \\
\hline $\begin{array}{l}\text { Sangat } \\
\text { Sesuai }\end{array}$ & 17 & 50 & \\
\hline \multicolumn{4}{|l|}{ Cara } \\
\hline \multicolumn{4}{|l|}{ Penyajian } \\
\hline Sesuai & 12 & 35,3 & \multirow[t]{2}{*}{$0,026^{*}$} \\
\hline $\begin{array}{l}\text { Sangat } \\
\text { Sesuai }\end{array}$ & 22 & 64,7 & \\
\hline \multicolumn{4}{|l|}{ Aroma } \\
\hline Sesuai & 15 & 44,1 & \multirow{2}{*}{0,223} \\
\hline $\begin{array}{l}\text { Sangat } \\
\text { Sesuai }\end{array}$ & 19 & 55,9 & \\
\hline \multicolumn{4}{|l|}{ Rasa } \\
\hline $\begin{array}{l}\text { Kurang } \\
\text { Sesuai }\end{array}$ & 1 & 2,9 & \multirow{3}{*}{$0,003 *$} \\
\hline Sesuai & 21 & 61,8 & \\
\hline $\begin{array}{l}\text { Sangat } \\
\text { Sesuai }\end{array}$ & 12 & 35,3 & \\
\hline \multicolumn{4}{|l|}{ Tingkat } \\
\hline \multicolumn{4}{|c|}{ Kematangan } \\
\hline Sesuai & 17 & 50 & \multirow[t]{2}{*}{0,226} \\
\hline $\begin{array}{l}\text { Sangat } \\
\text { Sesuai }\end{array}$ & 17 & 50 & \\
\hline \multicolumn{4}{|l|}{ Suhu } \\
\hline \multicolumn{4}{|l|}{ Penyajian } \\
\hline Sesuai & 18 & 52,9 & 0,335 \\
\hline $\begin{array}{l}\text { Sangat } \\
\text { Sesuai }\end{array}$ & 16 & 47,1 & \\
\hline
\end{tabular}


penilaian responden menyatakan bahwa warna makanan sangat sesuai sebanyak $52,9 \%$, bentuk makanan sangat sesuai sebanyak $52,9 \%$, konsistensi makanan sangat sesuai sebanyak $61,8 \%$, besar porsi sangat sesuai sebanyak $50 \%$, cara penyajian sangat sesuai sebanyak $64,7 \%$, aroma makanan sangat sesuai sebanyak $55,9 \%$, rasa makanan cukup sesuai sebanyak $61,8 \%$, dan suhu makanan saat penyajian cukup sesuai sebanyak $52,9 \%$. Meskipun sebagian besar responden memberikan penilaian baik terhadap penampilan makanan, namun nyatanya mayoritas responden masih menyisakan makanan. hal tersebut dapat disebabkan oleh faktor internal. Nafsu makan merupakan sensasi yang menyenangkan berupa keinginan seseorang untuk makan ${ }^{17}$. Perasaan tidak nyaman karena adanaya penyakit dapat menyebabkan seseorang kehilangan nafsu makan $^{10}$.

Penelitian ini menunjukkan bahwa suhu makanan saat penyajian tidak memiliki hubungan dengan sisa makanan selingan. Hal tersebut sesuai dengan penelitian di RSUD Kota Semarang oleh Angelina pada tahun 2017. Tidak ada hubungan suhu makanan dengan sisa makanan selingan diduga disebabkan karena hasil wawancara menunjukkan bahwa tidak ada responden yang menyatakan kurang sesuai dengan suhu makanan yang diberikan oleh pihak Rumah Sakit ${ }^{18}$. Dalam penelitian ini juga diketahui bahwa warna dan besar porsi makanan tidak berhubungan dengan sisa makanan selingan. Pernyataan ini sejalan dengan penelitian pada salah satu rumah sakit di Surabaya oleh Habiba tahun 2017 bahwa penilaian terhadap warna makanan tidak berhubungan dengan sisa makanan ${ }^{4}$. Sebagian responden memberikan tanggapan bahwa warna dan besar porsi sudah sesuai namun tetap saja menyisakan makanan yang cukup banyak. Pada penelitian Habiba diketahui bahwa kondisi depresi pasien memiliki hubungan yang signifikan dengan sisa makanan. pemilihan ataupun daya terima terhadap makanan dapat dipengaruhi oleh faktor psikologis. Semakin parah konsidi depresi pasien maka jumlah sisa makanan semakian banyak ${ }^{4}$. Maka dapat dikatakan bahwa faktor penampilan makanan.

Beberapa faktor yang mempengaruhi kualitas makanan yaitu penampilan dan rasa makanan $^{19}$. Faktor penampilan sangat mempengaruhi kesan pertama konsumen ${ }^{19}$. Sebagian besar responden merasa puas atau memberikan penilaian baik terhadap penampilan dan rasa makanan. hal tersebut menunjukkan bahwa makanan selingan pada pasiean anak di RUMKITAL Dr. Ramelan Surabaya memiliki kualitas yang baik jika dinilai dari segi penampilan dan rasa makanan.

hasil uji chi square untuk mengetahui hubungan antara Sembilan aspek penilaian makanan dengan sisa makanan selingan pada pasien anak menunjukkan bahwa hanya tiga aspek yang memiliki hubungan, yaitu bentuk makanan, cara penyajian, dan rasa makanan. penilaian penampilan makanan mempertimbangkan beberapa komponen yang terdiri dari warna, bentuk, besar porsi, dan cara penyajian. Rata-rata sisa makanan selingan responden menyatakan bentuk makanan sangat sesuai adalah $26,38 \%$.

Dalam penelitian ini, diketahui bahwa bentuk makanan berhubungan dengan sisa makanan selingan pada pasien anak $(p=0,046)$. Gambar 1 menunjukkan bahwa semakin baik penilaian responden terhadap bentuk maknan selingan, maka semakin sedikit sisa makanan selingan.

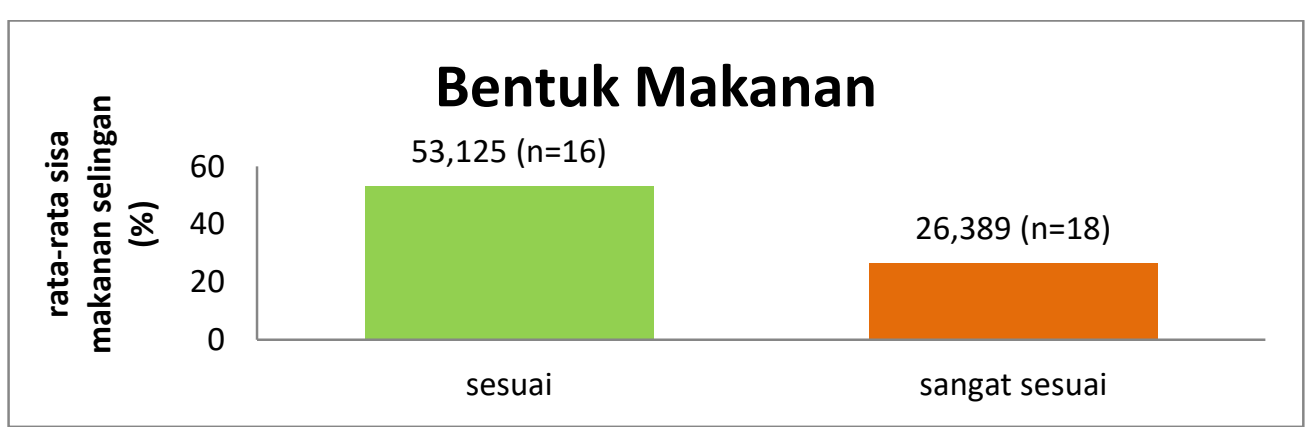

Gambar 1. Hubungan Bentuk Makanan dengan Sisa Makanan Selingan Pasien Anak 


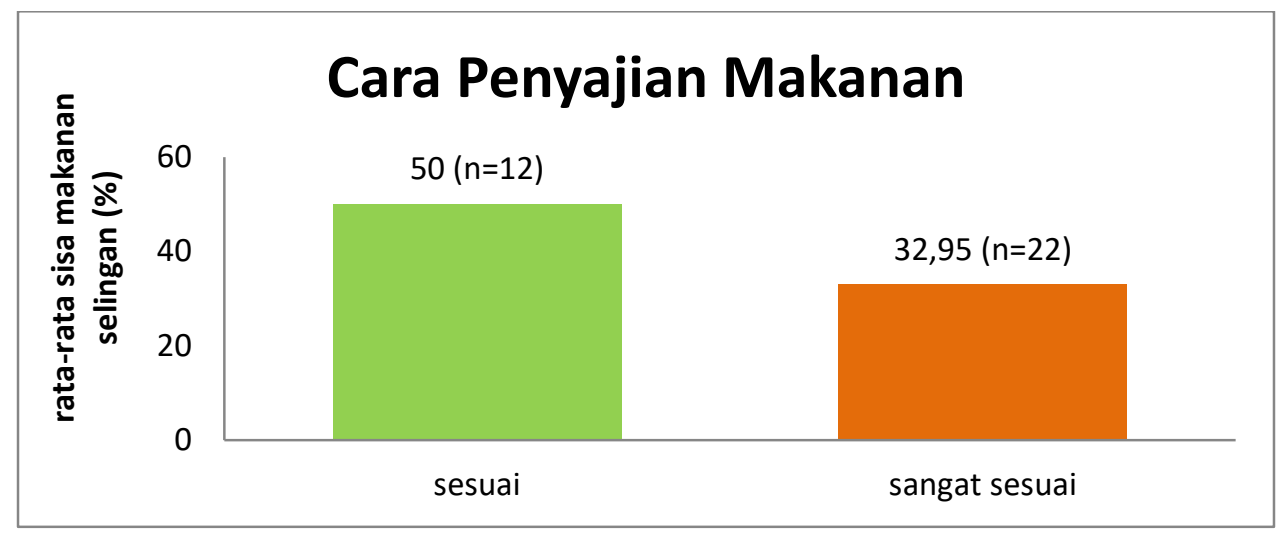

Gambar 2. Hubungan Cara Penyajian Makanan dengan Sisa Makanan Selingan Pasien Anak

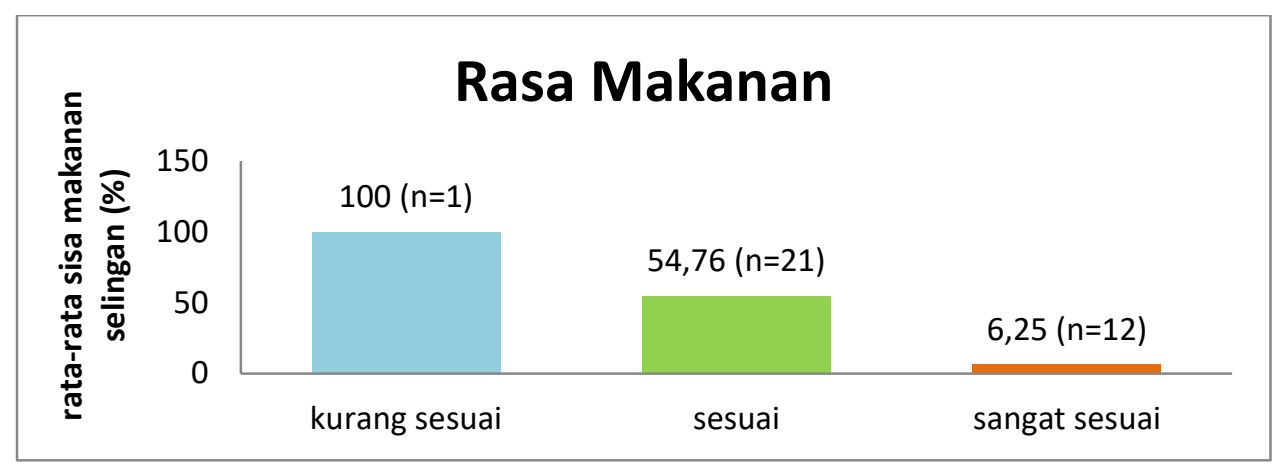

Gambar 3. Hubungan Rasa Makanan dengan Sisa Makanan Selingan Pasien Anak

Rata-rata sisa makanan selingan responden menyatakan cara penyajiannya sangat sesuai adalah $32,95 \%$. Hasil statistika menyatakan bahwa bentuk makanan berhubungan dengan sisa makanan selingan pada pasien anak $(p=0,046)$. Gambar 2 menunjukkan bahwa semakin baik penilaian responden terhadap cara penyajian makanan, maka semakin sedikit sisa makanan selingan. Pernyataan tersebut sesuai dengan penelitian di RSUD Sanglah Denpasar Provinsi Bali oleh Wirasamadi tahun 2015 bahwa penampilan makanan berhubungan dengan sisa makanan. pasien dengan sisa makanan sedikit cenderung menilai rasa dan penampilan makanan rumah sakit dalam kategori baik ${ }^{20}$.

Rasa merupakan sifat sensoris paling penting dari suatu produk makanan ${ }^{19}$. Responden yang menilai rasa makanan sangat sesuai memiliki ratarata sisa makanan selingan sebanyak 6,25\%. Hasil uji statistika menunjukkan bahwa rasa makanan berhubungan dengan sisa makanan selingan pada pasien anak $(0,003)$. Pada Gambar 3 menunjukkan bahwa semakin baik penilaian responden terhadap rasa makanan, maka semakin sedikit sisa makanan selingan. Hal ini sejalan dengan penelitian di RSUD Sanglah Denpasar bahwa pasien dengan sisa makanan sedikit cenderung menilai rasa makanan rumah sakit dalam kategori baik, dan sebaliknya ${ }^{20}$.

\section{KESIMPULAN}

Penelitian ini menunjukkan bahwa sebagian besar responden memberikan penilaian baik terhadap penampilan dan rasa makanan, namun mayoritas responden masih menyisakan makanan selingan (52,9\%). Jika dilihat dari faktornya, terdapat hubungan antara bentuk makanan, rasa makanan, dan cara penyajian dengan sisa makanan selingan pada pasien anak di RUMKITAL Dr. Ramelan Surabaya. Diharapkan kepada Sub Departemen Gizi di RUMKITAL Dr. Ramelan Surabaya agar tetap menjaga kualitas dan mutu makanan rumah sakit.

\section{ACKNOWLEDGEMENT}

Penulis mengucapkan terima kasih kepada seluruh staf pengajar program studi 
ilmu gizi Universitas Airlangga dan pihak Sub Departemen Gizi di RUMKITAL Dr. Ramelan Surabaya atas bimbingan dan bantuan selama pelaksanaan penelitian ini.

\section{REFERENSI}

1. Kementrian Kesehatan RI. Pedoman PGRS Pelayanan Gizi Rumah Sakit. Journal of Chemical Information and Modeling 53, 1689-1699 (2013).

2. Ariefuddin, M. Agus, D. Analisis Sisa Makanan Lunak Rumah Sakit pada Penyelenggaraan Makanan dengan Sistem Outsourcing di RSUD Gunung Jati Cirebon. Jurnal Gizi Klinik Indonesia 5, 133-142 (2009).

3. Menteri Kesehatan Republik Indonesia Nomor : $\quad$ 129/Menkes/SK/II/2008 Tentang Standar Pelayanan Minimal Rumah Sakit Menteri Kesehatan Republik Indonesia. Nomor Tambahan Lembaran Negara Nomor 4355 Nomor Tambahan Lembaran Negara Nomor 4400 doi:10.1017/СВ09781107415324.004

4. Habiba, R. A. \& Adriani, M. Hubungan Depresi, Asupan, dan Penampilan Makanan dengan Sisa Makan Pagi Pasien Rawat Inap (Studi di Rumah Sakit Islam Jemursari Surabaya). Amerta Nutrition 1, 198-208 (2017).

5. Fatkhuroman, D. Hubungan Perubahan Standar Porsi Makan dengan Sisa Makanan Pasien Rumah Sakit Holistik Tahun 2016. Journal of the Indonesian Nutrition Association 40, 1-8 (2017).

6. Paruntu, O. L. Status Gizi dan Penyelenggaraan Makanan Diet Pasien Rawat Inap di Blu Prof. Dr. R.D. Kandou Manado. Jurnal Gizi Indonesia 5, (2013).

7. Kesuma, A., Novayelinda, R. \& Sabrian, F. Faktor-faktor yang berhubungan dengan perilaku kesulitan makan anak prasekolah. Jurnal Online Mahasiswa 2, 953-961 (2015).

8. Soedibyo, S. \& Mulyani, R. L. Kesulitan Makan pada Pasien: Survei di Unit Pediatri Rawat Jalan. Sari Pediatri 11, 79-84 (2009).

9. Williams, P. \& Walton, K. Plate waste in hospitals and strategies for change. $e$ SPEN

doi:10.1016/j.eclnm.2011.09.006

10. Valero Díaz, A. \& Caracuel García, Á. Evaluación de factores influyentes sobre el desecho de alimentos por parte de pacientes procedentes de diferentes recintos hospitalarios. Nutricion Hospitalaria 28, 419-427 (2013).

11. semedi, P. \& Kartasurya, M. I. Hubungan kepuasan pelayanan makanan rumah sakit dan asupan makanan dengan perubahan status gizi pasien (Studi di RSUD Sunan Kalijaga Kabupaten Demak). 2, 32-41 (2013).

12. Alooh, O. A. Quantifying food plate waste: case study of a university dining facility. 1-97 (2015).

13. Menteri Kesehatan Republik Indonesia. Permenkes Nomor 78 Tahun 2013 tentang Pedoman Pelayanan Gizi Rumah Sakit. Permenkes (2013).

14. Lumbantoruan, D. B. S. Hubungan Penampilan Makanan dan Faktor Lainnya dengan Sisa Makanan Biasa Pasien Kelas 3 Seruni RS Puri Cinere Depok Bulan April-Mei 2012. [skripsi] Universitas Indonesia (2012).

15. Rijadi, C. B. Hubungan Rasa Penampilan Makanan dan Faktor Lainnya Terhadap Daya Terima Makanan Lunak Pada Pasien Dewasa di Gedung Perawatan Umum RSPAD Gator Soebroto (Skripsi). 10 (2012).

16. Catering, N. \& Specification, N. Food in hospitals. British Medical Journal 2, 1283-1284 (1963).

17. Adrianai, M., Wirjatmadi, B. Pengantar Gizi Masyarakat. (2014).

18. Nareswara, A. S. Hubungan Kepuasan Pasien dari Kualitas Makanan Rumah Sakit dengan Sisa Makanan di RSUD Kota Semarang. IImu Gizi Indonesia 01, 34-39 (2017).

19. Molnár, P. J. Food Quality Indices. Food Quality and Standards II, (2009).

20. Wirasamadi, N. L. P. et al. Analisis Sisa Makanan Pasien Rawat Inap di RSUP Sanglah Denpasar Provinsi Bali. Laporan Penelitian 3, 88-95 (2015). 